\title{
First Impressions of the Face: Predicting Success
}

\author{
Nicholas Rule and Nalini Ambady* \\ Tufts University
}

\section{Abstract}

The human tendency to form impressions of others is ubiquitous and consequential. Consensus, or agreement among individuals, regarding their first impressions based on the facial appearance of others can lead to the treatment of other individuals in particular ways that shape their outcomes and behaviors. For an impression to be considered accurate it must not only be consensual but must also show correspondence to an external criterion, such as whether impressions of individuals' leadership ability are related to the performance of their group or organization. Many of our first impressions may not have valid external criteria to enable an assessment of the accuracy of the impression. Yet, whether our impressions are accurate or merely consensual, they can still often predict important outcomes. A limited but growing literature has shown that our impressions can be both consensual and predictive despite important social and perceptual distinctions, such as differences in culture.

\section{First Impressions of the Face: Predicting Success}

Whether walking along a busy street, shopping for groceries at the market, or riding a commuter train or bus, we are constantly encountering other people and forming impressions of them. Humans are predisposed toward making snap judgments about others and sorting them into social categories in the service of simplifying the social world of which we are part (Ambady, Bernieri, \& Richeson, 2000). Although some of the impressions we make may be fallacious (such as mistaking a long-haired man for a woman at first glance; Macrae \& Martin, 2007), others can be quite accurate (such as accurately judging a man's sexual orientation from a glimpse of his face; Rule \& Ambady, 2008a).

Even when our impressions of others turn out to be inaccurate, however, they can be powerful determinants of how we behave toward others and, in turn, how we treat others can sometimes dramatically influence their lives. For example, Clifford and Walster (1973) found that teachers believed attractive children to have more potential for success than unattractive students. Moreover, Rosenthal and Jacobson (1968) reported that teachers' expectations about their students' learning ability substantially impacted the children's actual academic success. Thus, a teacher's impression of a child's attractiveness might possibly have more influence on her progress in school than her actual intelligence.

In this article we review some of the consequences that can come from our first impressions of others. In doing so, we restrict ourselves to the primary channel through which our nonverbal behaviors are expressed and our impressions inferred: the face (Rinn, 1991; Zebrowitz, 1997). Although other cues from nonverbal behavior, such as the body (Johnson \& Tassinary, 2005) and the voice (Gaertner, 1973; Scherer, Johnstone, \& Klasmeyer, 2003) each may provide cues informative to our impressions of others, the face is unmistakably unique. Evidence for this comes not only from a vast literature of empirical studies showing that individuals' faces influence our impressions and dispositions 
toward them (Zebrowitz, 1997) but also from studies in neuroscience showing that faces are privy to specialized processing in the brain (Kanwisher, 2000).

\section{Accuracy and consensus}

When are impressions of others predictive of their behaviors or outcomes? To determine whether an impression of another can be regarded as accurate typically requires a criterion that is objective, or uninfluenced by the process through which we form our impression (see Funder, 1987; Funder \& West, 1993). In everyday life such criteria are often hard to come by. But even in the absence of external criteria, there are often instances when our impressions agree with others' impressions of the same individuals. This agreement or consensus is sometimes considered to be an index of accuracy. Consensual judgments are consequential and can be powerful indicators of how individuals are treated (e.g., Dion, Berscheid, \& Walster, 1972). Consensual judgments can also be flawed. For instance, individuals may agree in their impression that someone looks honest and likeable (as in the case of Bernard Madoff discussed later in this article) but this impression may be difficult to validate without an objective measure of honesty and likeability.

\section{Consensus from the Face}

Even across diverse groups of perceivers and targets (such as differences in age, racial, or cultural group membership), individuals may show high agreement for particular judgments. One domain in which consensus has been well-explored is that of personality judgments. Albright et al. (1997), for instance, showed that American and Chinese perceivers agreed in their judgments of American and Chinese targets for the 'Big 5' personality traits of extraversion, conscientiousness, agreeableness, culture/openness to experience, and emotional stability/neuroticism. The American perceivers agreed with the other American perceivers' impressions of both the American and Chinese targets and the Chinese perceivers agreed with the other Chinese perceivers' impressions of both the Chinese and American targets. In addition, the American and Chinese perceivers agreed with one another in their impressions of the extraversion of other American and Chinese targets.

Other researchers have also found that observers' impressions can sometimes agree with targets' own impressions of their personality. For example, Penton-Voak, Pound, Little, and Perrett (2006) found that strangers' impressions of targets' extraversion were significantly correlated with the targets own self-reported extraversion on a personality questionnaire. This consensus between strangers' impressions of an individual's traits and her own self-reported traits are sometimes believed to be an indicator that the judgments are accurate. However, the use of self-report measures as a criterion for accuracy is debated, as self-reports can be unreliable (e.g., Ambady \& Rosenthal, 1992; Funder \& West, 1993).

Perceivers tend to agree in their judgments of facial physiognomy. In particular, individuals show high agreement in their judgments of others' attractiveness and facial maturity (Zebrowitz, 1997). Facial attractiveness is one of the most powerful predictors of how individuals are treated and perhaps the most thoroughly studied. Attractive individuals are treated more positively than unattractive individuals (Dion et al., 1972; Griffin \& Langlois, 2006). Specifically, attractive people are usually perceived as more intelligent, more socially competent, and more emotionally stable, although not as more considerate 
(Eagly, Ashmore, Makhijani, \& Longo, 1991). This is true for both children and adult perceivers and targets, does not differ whether the perceivers are familiar or unfamiliar with the target, and occurs regardless of the amount of other information the perceiver has available when forming an impression (Langlois et al., 2000). Importantly, this bias in favor of attractive faces affects how individuals are treated (Clifford \& Walster, 1973) and has a pronounced effect upon outcomes, such as job opportunities and advancement (Hosoda, Stone-Romero, \& Coats, 2003).

Facial maturity does not refer to judgments of age but is an age-independent trait that describes the babyishness or maturity of an individual's face (Zebrowitz \& Montepare, 1992). A 'babyface' is defined as one with neotenous features, such as a large forehead, high eyebrows, large eyes, nonprominent cheekbones, and a small jaw (e.g., Zebrowitz, Montepare, \& Lee, 1993a). In contrast, mature faces are generally characterized by a small forehead, heavy brow ridge, prominent cheekbones, and a large jaw. Individuals with babyish versus mature faces are often believed to be submissive, naive, weak, warm, and honest qualities similar to those ascribed to infants. Mature-faced persons, in contrast, are often seen as dominant, shrewd, powerful, competent, and untrustworthy (Berry \& McArthur, 1985). Perceivers' responses to these cues are so strong that they have been shown to influence targets' employment opportunities (Collins \& Zebrowitz, 1995) and litigation outcomes in court (Zebrowitz \& McDonald, 1991). Thus, impressions of facial maturity have important consequences for how individuals are treated.

\section{Accuracy from the Face}

Not only do individuals' impressions sometimes show high agreement, there are also instances in which these consensual impressions can be validated as accurate. As mentioned earlier, the confirmation that a judgment is accurate typically requires a criterion that is unaffected by the judgmental process. For example, Todorov, Mandisodza, Goren, and Hall (2005)reported that perceivers' impressions of the faces of U.S. political candidates predicted the percentage of votes that the candidates received in their actual elections. Thus, judgments of faces in the laboratory can predict real-world outcomes. Yet, because the outcome criterion was based on voters' consensus, the judgmental process in the laboratory (participants' subjective impressions of the candidates) and the external outcome (voters' subjective impressions of the candidates) were quite similar - particularly when considering that the participants in the lab also belong to the larger group of voters determining the criterion.

In other cases, judgments in which perceivers' subjective impressions are dissociated from the outcome criterion (i.e., the process by which the perceivers come to form their impressions is distinct from the process by which the outcome came to be). Following the Holocaust, a number of researchers explored perceivers' ability to accurately judge whether a target was Jewish or non-Jewish based on facial appearance (see Rice \& Mullen, 2003 for a review). Overall, perceivers were able to categorize the Jewish and non-Jewish targets according to their group membership significantly better than would be expected from chance guessing. Perceivers' subjective impressions as to whether a target looked Jewish or non-Jewish were therefore related to an objective criterion: the targets' actual group membership. Similar effects have been found for another social category of sexual orientation. In a series of studies, we have found, together with several colleagues, that men's and women's sexual orientation can be judged at above-chance levels from their faces in just a fraction of a second (e.g., Rule, Ambady, \& Hallett, 2009). Even impressions of sexual orientation from individual facial features (such as 
targets' eyes) significantly relate to self-identified sexual orientation (e.g., Rule, Ambady, Adams, \& Macrae, 2008).

For both categorizations, perceivers showed high consensus as to whom they believed to be members of the two groups. Beyond simply agreeing about which targets they believed to be Jewish and non-Jewish, however, the perceivers' judgments also corresponded to the targets' true group membership. This is a straightforward example of how impressions can be verified as accurate. For other impressions, however, there are relationships between subjective impressions and objective outcomes that are not as clear. Indeed, there are many cases in which subjective impressions can be predictive of outcomes and hold important consequences but in which the relationships between the impressions and outcomes are indirect.

\section{Predicting Outcomes from the Face}

Consensus and accuracy are both important components in assessing the predictive validity of first impressions. As discussed earlier, consensus is usually a prerequisite for accuracy: perceivers must agree in their impressions for the aggregate effect of their impressions to be accurate. But agreement is not always associated with accuracy.

Consider the case of Bernard Madoff, engineer of the most damaging Ponzi scheme to date. If one assumes that individual investors entrust their finances to persons they deem trustworthy, then the consensus impression of trustworthiness is sufficient to predict with whom individuals will invest their money. Madoff gained the trust of many and excelled in securing investments. As many of those who trusted him painfully discovered, Madoff was not at all trustworthy. The subjective impressions of many that Madoff was trustworthy predicted an important outcome - his ability to secure investments. Unfortunately, those consensual impressions proved to be inaccurate.

\section{Predicting subjective outcomes}

Although we do not know whether it is investors' sense of bankers' trustworthiness that determines with whom they invest their money, the Madoff anecdote serves as an example of how perceivers' impressions can predict subjective outcomes. Here the outcome (how many people trust a banker with their money) is directly related to the impression made (how trustworthy the banker appears). Subjective impressions can predict important subjective outcomes. For instance, impressions of individuals' facial maturity predict their job opportunities because their interviewers are influenced by the same impressions of facial maturity (Collins \& Zebrowitz, 1995).

In a recent study we examined the effects of cultural familiarity on impressions of political candidates. We asked American perceivers to judge the faces of candidates from an election with whom they were entirely unfamiliar: the 2004 election of the Canadian parliament. Forty-five American undergraduates rated the faces of the 38 candidates from the election on five traits (competence, dominance, facial maturity, likeability, and trustworthiness) along seven-point scales anchored at 'Not at all X' (1) and 'Very X' (7). Participants showed high consensus in their judgments of the targets (all Cronbach's $\alpha$ inter-rater reliabilities $>0.89$ ). Ratings of competence, dominance, and facial maturity loaded together onto one factor in a principal components factor analysis with varimax rotation (all factor loadings $>0.67 ; 42 \%$ of variance explained) and likeability and trustworthiness loaded together on a second factor (both factor loadings $>0.89$; $43 \%$ of 
variance explained). We therefore averaged participants' scores for these traits into composites that we will refer to as Power and Warmth, respectively.

To measure whether the participants' judgments were predictive, we correlated each perceiver's power and warmth scores for each candidate with a vector coded 0 and 1 depending on whether the candidate lost $(n=18)$ or won $(n=20)$ the election. The mean correlation between power and electoral outcome for the individual perceivers was 0.08 with a $95 \%$ confidence interval ranging between 0.06 and 0.10 . The mean correlation between warmth and electoral outcome for the individual perceivers was -0.15 with a 95\% confidence interval ranging between -0.12 and -0.18 . As neither confidence interval contained 0 , both effects may be regarded as significant at $\alpha=0.05$ (see Rule et al., 2008, for details on this type of analysis). These data therefore show that American participants' impressions of power from Canadian political candidates' faces positively predicted their electoral success - the more powerful they looked, the more likely they were to win the election - and their impressions of warmth negatively predicted their electoral success - the more warm they looked, the less likely they were to win the election. Notably, these effects remained significant and similar in size if women and racial minority candidates are excluded from analysis.

In this example, American participants showed high consensus in the way that they perceived the faces of political candidates from a different culture. Additionally, although the perceivers did not know the identities of any of the candidates and were not told that they were rating the faces of politicians, the individual perceivers' subjective impressions significantly corresponded to the election's outcome. Subjective impressions therefore predicted an important outcome. But are these impressions accurate?

Determining the accuracy of these judgments is muddled by two important limitations. We have mentioned one such limitation already: Perceivers' impressions of the candidates' faces might be the cause of whether or not they are elected. If voters cast their ballots according to their impressions of the candidates, then the observation that a subset of potential voters' impressions in the laboratory replicates the election's outcome is not surprising. In this instance, the American participants were not voters in the Canadian election. However, given the similarities between Canadian and American culture, the impressions of Americans and Canadians probably do not greatly differ. Thus, the Americans' impressions might possibly be representative of Canadian perceivers' potential impressions.

The second limitation is that, to consider whether these impressions are accurate, we must assume that there is a relationship between impressions of candidates' personalities and their actual personalities. One aspect of this question that complicates things further is how power, warmth, and their constituent traits might be defined and assessed. What makes a person likeable, competent, or trustworthy? Just because we agree about whether a person looks babyfaced, for example, and we treat that person according to the stereotypes associated with babyfaced persons, this does not necessarily mean that the person's behaviors will actually be consistent with those stereotypes (see Zebrowitz, Andreoletti, Collins, Lee, \& Blumenthal, 1998 for data demonstrating this). It can therefore be difficult or impossible to validate whether some traits judgments are accurate, even though they may be highly consequential and predictive of important outcomes.

\section{Predicting objective outcomes}

There are other domains, however, in which the outcomes do match traits. If, for example, we asked perceivers to assess how effective a target might be as a leader and had 
evidence for the targets' actual leadership ability, we may be able to say whether the impression was accurate. Indeed, just such a relationship has been found in previous studies (Rule \& Ambady, 2008b, 2009) and illustrate this with some data later.

We collected photographs of the faces of the Chief Executive Officers (CEOs) of the 100 best American companies in 2007, as determined by Fortune magazine's annual rankings (i.e., the Fortune 100). We cropped the photographs to remove clothing and standardized each photograph for size and image quality. We then asked 30 undergraduates to rate each face for how successful they believed the individual would be at leading a company on a scale from 1 'Not at all successful' to 7 'Very Successful'. One participant recognized a CEO and was removed from analysis. The remaining 29 perceivers showed high agreement in their impressions of the CEOs (Cronbach's $\alpha=0.82)$.

To determine whether their judgments were predictive, we correlated each participant's ratings of the faces with a measure of the CEOs' success at leading their companies: the amounts of net profits that the companies made that year. The mean correlation across participants was 0.06 with a 95\% confidence interval spanning $0.03-0.09$, indicating that the correspondence between the perceivers' impressions of leadership success and the actual performance of the leaders' groups (measured via how much profit they made) was significant at $\alpha=0.05$. The significance of this relationship remains even after controlling for the CEOs' ages, their facial expressions in the photographs, their facial attractiveness, and when excluding companies with profits that were greatly in excess of the group's mean (such as the oil company Exxon-Mobil whose profits were more than seven times greater than the average of the other 99 companies).

These data show evidence for subjective impressions of leadership ability predicting a relevant outcome that is unrelated to the perceivers' impressions. First, impressions of an individual's leadership ability are relevant to the leader's actual demonstrated ability to lead his group. Although there are many mediating variables between a CEO's face and the performance of his company, a company's financial performance is often considered the gold standard for measuring the effectiveness of its CEO (Kaiser, Hogan, \& Craig, 2008). Thus, the relationship between the measure and the criterion may be considered valid.

Second, perceivers' impressions of a CEO's leadership ability bear relatively no causal influence on his or her company's success. Although there are anecdotal instances in which some consumers might endorse a company's products because of affection for its CEO (such as buying an Apple computer out of respect for the company's CEO and founder Steve Jobs), these occasions are likely to be rare. Indeed, most company CEOs are not well known in the popular market. Thus, unlike the influence of perceivers' impressions upon their decisions for whom to vote, there is little or no reason to believe that consumers' impressions of CEOs are related to whether one purchases their products or services.

In contrast, company employees may be influenced by their impression of their CEO's leadership ability. This may possibly influence their motivation and effort, which may have a direct impact upon how the overall organization performs. Although there are other factors that contribute to a company's performance aside from its CEO, this does not mean that the CEO cannot significantly contribute to explaining the variance between individual companies' success, as we found here. Our data suggest that impressions of the CEO do matter and are related to company performance.

The difference between the examples of CEOs and politicians therefore lies in the criteria. Specifically, does the criterion reflect subjective characteristics (such as voters' 
opinions) or objective characteristics (such as business profitability)? Both share the quality of consensus, but objective criteria reflect accuracy beyond consensus.

\section{Qualities of the Face}

The relationships between impressions and the prediction of both subjective and objective outcomes in the previous two examples may seem somewhat puzzling. What are the qualities are in the faces that distinguish candidates according to competence or power? What the facial features lead one to believe that someone is a better leader than another? For some traits, the features that influence impressions are well known and are supported by evolutionary theories for why the traits are associated with their resultant impressions.

One trait that exerts a powerful influence upon impressions is facial maturity. As discussed earlier, individuals with neotenous features are believed to possess the behavioral qualities and traits of babies. The process responsible for this effect is referred to as overgeneralization (Zebrowitz \& Montepare, 2006). That is, attributes from one class of stimuli (babies) are associated with qualities realistically descriptive of that class (e.g., naivete). The association between babies and the traits that describe babies, however, is then overgeneralized to a second class that bears familiarity to the first class. That is, the association between looking babyish and babies' naivete is ascribed to adults who look babyish, such that they too are perceived to be more naive than others - even to the extent that they are sometimes spoken to in 'baby talk' (Zebrowitz, Brownlow, \& Olson, 1992).

As described earlier, there are clear physical traits that make a face appear babyish versus mature. Moreover, these are qualities of the face that exist relatively independent of age and can persist within the individuals over the course of their lives (Zebrowitz, Olson, \& Hoffman, 1993b). Thus, babyface-definitive facial features (e.g., eye size and brow height) influence both perceptions and behavior. For instance, babyfaced adults compared to more mature-faced adults are favored in court when accused of intentionally harming another person because the appearance of the babyfaced person is incongruent with the intention to harm, causing others to believe that the babyfaced person's actions must have been accidental (Zebrowitz \& McDonald, 1991). Thus, perceivers' subjective impressions of facial maturity are based upon a well-defined set of physical features and are perceived consistently. Although the impressions may be fallacious (e.g., Zebrowitz et al., 1998), they exert powerful effects that can be easily predicted based on facial structure. The outcomes are therefore predictable but subjectively based upon stereotypes.

Another well-defined facial quality that predicts behaviors is facial dominance. The cues to facial dominance are similar to those of facial maturity (e.g., a large jaw and heavy brow ridge) and can influence how other facial qualities are perceived, such as attractiveness and emotional expression (Keating, 1985; Ohman, 1986). Impressions of dominance have strong influences upon social interaction and the establishment of status hierarchies (Mazur, 2005). Mueller and Mazur (1996)conducted a study measuring the facial dominance of students from the U.S. military academy at West Point and examined its relationship to the success of their military careers. Undergraduates were presented with the graduation portraits of West Point cadets and asked to rate their faces from submissive to dominant. Cadets with more dominant faces achieved higher military ranks, and these effects were more pronounced among the highest ranking officers. Subjective impressions of dominance based on facial cues therefore predicted an objective measure of career success in the military (rank achieved). Mazur and colleagues (Mazur, 2005; Mueller \& Mazur, 1996) suggest that this may be because dominance has become associated with physical prowess over the course of primate evolution such that more physically 
dominant individuals are perceived as more capable of conducting and leading aggressive acts, such as war.

\section{Target and Perceiver Culture}

Impressions of individuals from faces may predict how they are treated by others as well as their success. Most of the research documenting this comes from targets and perceivers who share the same cultural background. Culture could be an important mitigating factor in the relationship between impressions of individuals and their resultant consequences. Here we briefly review what is currently known about consensus, accuracy, and prediction of outcomes based on judgments of facial appearance when the targets and perceivers come from different cultures.

\section{Consensus}

Several studies have shown evidence for consensus in impressions of faces across cultures. Albright et al. (1997) showed consensus in the ratings of personality traits among targets and perceivers from China and the United States. Cunningham, Roberts, Barbee, Druen, and $\mathrm{Wu}$ (1995) found that judgments of attractiveness from faces were consistent across American and Taiwanese perceivers for an internationally diverse set of targets. And Zebrowitz et al. (1993a) demonstrated similarity in the impressions and behavioral attributions made to faces of African-American, European-American, and Korean targets and perceivers for various personality and physiognomic (i.e., facial maturity and facial attractiveness) traits. Thus, perceivers seem to agree in their judgments of diverse targets on a number of traits regardless of their own or the targets' cultures.

\section{Accuracy}

The area of experimental research that is perhaps best-studied cross-culturally is that of accuracy in emotion recognition. From the early studies by Ekman and colleagues (e.g., Ekman, 1980; Ekman, Sorensen, \& Friesen, 1969) showing relative universality in the expression and perception of emotion, the demonstration of accuracy in the cross-cultural encoding and decoding of emotions has been well verified. There is also evidence for cultural specificity. For instance, Elfenbein and Ambady (2003) found evidence for an ingroup advantage in emotion recognition. That is, individuals may be better at interpreting the emotional expressions of cultural ingroup members than of cultural outgroup members, despite being accurate for both groups (see also Matsumoto, Olide, \& Willingham, 2009). At present, however, almost all studies examining the accuracy of judgments of faces across cultures have studied emotion recognition.

\section{Predicting outcomes}

Cross-cultural consensus in trait impressions suggests that the outcomes of these impressions would be consistent. Indeed, several studies have shown instances of predicting outcomes across cultures.

Similar to the Canadian data reported earlier, Poutvaara, Jordahl, and Berggren (2009) found that judgments of facial competence made in an international web survey of Finnish electoral candidates significantly predicted the outcomes of elections. Thus, subjective impressions from members of various (mostly Western) cultures indirectly predicted the 
subjective impressions that led to electoral outcomes for targets in another Western culture. Similarly, Antonakis and Dalgas (2009) found that Swiss children's judgments of leadership of French political candidates predicted their electoral success. Thus, the subjective impressions of children from one Western culture predicted the subjective but consequential impressions of adults from a similar Western culture. Finally, Rule et al. (in press) examined trait judgments and voting judgments made by American and Japanese perceivers of political candidates in both their own and the other's culture. American and Japanese perceivers showed cross-cultural consensus in their ratings of the targets from both cultures and impressions of the traits predicted electoral success in both nations, although the traits markedly differed (power predicted the percentage of votes that American candidates received whereas warmth predicted the percentage of votes that Japanese candidates received). When making explicit judgments about voting behavior, however, perceivers only predicted their own culture's electoral outcomes. For example, Americans' estimations of who other Americans would vote for were consistent with who won the election (i.e., who they actually did vote for) but Americans' estimations of who Japanese would vote for were not consistent with who won the election. Thus, although impressions may be consistent across nations and cultures, in some domains cultural knowledge may be necessary for predicting the outcomes that accord with those impressions.

\section{Conclusion}

Our tendency to form impressions of others based on facial appearance is constant and ubiquitous. Generally, we agree in the ways that we perceive one another. This agreement sometimes must stand on its own as shared opinion but in some cases these judgments can be verified as accurate or inaccurate. Regardless of accuracy, however, these impressions can be consequential. They can lead us to assume and attribute characteristics and dispositions in others that affect their successes and opportunities and can predict large-scale outcomes, such as electoral decisions, that ultimately affect us all. Subjective impressions can therefore predict both subjectively created and objectively based criteria. For some traits we know what cues and features trigger these impressions and effects but for many of our impressions these components remain unknown. Finally, these impressions are formed and sometimes validated regardless of our culture or the cultural group membership of those we perceive. Thus, from the most mundane afternoon on a park bench to the stress of a tense job interview, we are actively evaluating and forming impressions about others for a host of traits, both important and insignificant.

\section{Short Biographies}

Nicholas Rule is an Assistant Professor at the University of Toronto. He received his Ph.D. from Tufts University in 2010. He is a recipient of the Tufts University Graduate School of Arts \& Sciences Award for Outstanding Academic Achievement.

Nalini Ambady, Professor and Neubauer Faculty Fellow at Tufts University, received her Ph.D. in social psychology from Harvard University and taught at Holy Cross College and Harvard University, where she was the John and Ruth Hazel Associate Professor of the Social Sciences, before moving to Tufts. She is the recipient of the Presidential Early Career Award for Scientists and Engineers (1999), the American Association for the Advancement of Science, Behavioral Science Research Award (1993), the APA Division 5 (Evaluation, Measurement, \& Statistics) Dissertation Award (1994) and Northeast Association of Graduate Schools Mentoring Award (2008). 


\section{Endnote}

* Correspondence address: Nalini Ambady, Tufts University, Dept. of Psychology, Medford MA 02155, USA. Email: nalini.ambady@tufts.edu

\section{References}

Albright, L., Malloy, T. E., Dong, Q., Kenny, D. A., Fang, X., Winquist, L., et al. (1997). Cross-cultural consensus in personality judgments. Journal of Personality and Social Psychology, 72, 558-569.

Ambady, N., Bernieri, F. J., \& Richeson, J. A. (2000). Toward a histology of social behavior: Judgmental accuracy from thin slices of the behavioral stream. Advances in Experimental Social Psychology, 32, 201-271.

Ambady, N., \& Rosenthal, R. (1992). Thin slices of expressive behavior as predictors of interpersonal consequences: A meta-analysis. Psychological Bulletin, 111, 256-274.

Antonakis, J., \& Dalgas, O. (2009). Predicting elections: Child's play! Science, 323, 1183.

Berry, D. S., \& McArthur, L. Z. (1985). Some components and consequences of a babyface. Journal of Personality and Social Psychology, 48, 312-323.

Clifford, M. M., \& Walster, E. H. (1973). The effect of physical attractiveness on teacher expectation. Sociology of Education, 46, 248-258.

Collins, M. A., \& Zebrowitz, L. A. (1995). The contributions of appearance to occupational outcomes in civilian and military settings. Journal of Applied Social Psychology, 25, 129-163.

Cunningham, M. R., Roberts, A. R., Barbee, A. P., Druen, P. B., \& Wu, C. (1995). "Their ideas of beauty are, on the whole, the same as ours": Consistency and variability in the cross-cultural perception of female physical attractiveness. Journal of Personality and Social Psychology, 68, 261-279.

Dion, K., Berscheid, E., \& Walster, E. (1972). What is beautiful is good. Journal of Personality and Social Psychology, 24, 285-290.

Eagly, A. H., Ashmore, R. D., Makhijani, M. G., \& Longo, L. C. (1991). What is beautiful is good, but...: A meta-analytic review of research on the physical attractiveness stereotype. Psychological Bulletin, 110, 109-128.

Ekman, P. (1980). The Face of Man: Expressions of Universal Emotions in a New Guinea Village. New York: Garland STPM Press.

Ekman, P., Sorensen, E. R., \& Friesen, W. V. (1969). Pancultural elements in facial displays of emotions. Science, 164, 86-88.

Elfenbein, H. A., \& Ambady, N. (2003). Universals and cultural differences in recognizing emotions of a different cultural group. Current Directions in Psychological Science, 12, 159-164.

Funder, D. C. (1987). Errors and mistakes: Evaluating the accuracy of social judgment. Psychological Bulletin, 101, 75-90.

Funder, D. C., \& West, S. G. (1993). Consensus, self-other agreement, and accuracy in personality judgment: An introduction. Journal of Personality, 61, 457-476.

Gaertner, S. L. (1973). Helping behavior and racial discrimination among liberals and conservatives. Journal of Personality and Social Psychology, 25, 335-341.

Griffin, A. M., \& Langlois, J. H. (2006). Stereotype directionality and attractiveness stereotyping: Is beautiful good or is ugly bad? Social Cognition, 24, 187-206.

Hosoda, M., Stone-Romero, E. F., \& Coats, G. (2003). The effects of physical attractiveness on job-related outcomes: A meta-analysis of experimental studies. Personnel Psychology, 56, 431-462.

Johnson, K. L., \& Tassinary, L. G. (2005). Perceiving sex directly and indirectly: Meaning in motion and morphology. Psychological Science, 16, 890-897.

Kaiser, R. B., Hogan, R., \& Craig, S. B. (2008). Leadership and the fate of organizations. American Psychologist, 63, 96-110.

Kanwisher, N. (2000). Domain specificity in face perception. Nature Neuroscience, 3, 759-763.

Keating, C. F. (1985). Gender and the physiognomy of dominance and attractiveness. Social Psychology Quarterly, 48, 61-70.

Langlois, J. H., Kalakanis, L., Rubenstein, A. J., Larson, A., Hallam, M., \& Smoot, M. (2000). Maxims or myths of beauty? A meta-analytic and theoretical review. Psychological Bulletin, 126, 390-423.

Macrae, C. N., \& Martin, D. (2007). A boy primed Sue: Feature-based processing and person construal. European Journal of Social Psychology, 37, 793-805.

Matsumoto, D., Olide, A., \& Willingham, B. (2009). Is there an ingroup advantage in recognizing spontaneously expressed facial expressions? Journal of Nonverbal Behavior, 33, 181-191.

Mazur, A. (2005). The Biosociology of Dominance and Deference. Lanham, MD: Rowman \& Littlefield.

Mueller, U., \& Mazur, A. (1996). Facial dominance of West Point cadets as a predictor of later military rank. Social Forces, 74, 823-850.

Ohman, A. (1986). Face the beast and fear the face: Animal and social fears as prototypes for evolutionary analyses of emotion. Psychophysiology, 23, 123-145. 
Penton-Voak, I. S., Pound, N., Little, A. C., \& Perrett, D. I. (2006). Personality judgments from natural and composite facial images: More evidence for a "kernel of truth" in social perception. Social Cognition, 24, 607640 .

Poutvaara, P., Jordahl, H., \& Berggren, N. (2009). Faces of politicians: Babyfacedness predicts inferred competence but not electoral success. Journal of Experimental Social Psychology, 45, 1132-1135.

Rice, D. R., \& Mullen, B. (2003). Isaac, Ishmael, and Janus: Past and future lessons regarding the ethnic categorization of faces. Applied Cognitive Psychology, 17, 1129-1147.

Rinn, W. E. (1991). Neuropsychology of facial expression. In R. S. Feldman \& B. Rime (Eds.), Fundamentals of Nonverbal Behavior (pp. 3-30). New York: Oxford University Press.

Rosenthal, R., \& Jacobson, L. (1968). Pygmalion in the Classroom: Teacher Expectations and Student Intellectual Development. New York: Holt, Rinehart, \& Winston.

Rule, N. O., \& Ambady, N. (2008a). Brief exposures: Male sexual orientation is accurately perceived at $50 \mathrm{~ms}$. Journal of Experimental Social Psychology, 44, 1100-1105.

Rule, N. O., \& Ambady, N. (2008b). The face of success: Inferences from chief executive officers' appearance predict company profits. Psychological Science, 19, 109-111.

Rule, N. O., \& Ambady, N. (2009). She's got the look: Inferences from female chief executive officers' faces predict their success. Sex Roles. DOI: 10.1007/s11199-009-9658-9.

Rule, N. O., Ambady, N., Adams, R. B. Jr, \& Macrae, C. N. (2008). Accuracy and awareness in the perception and categorization of male sexual orientation. Journal of Personality and Social Psychology, 95, 1019-1028.

Rule, N. O., Ambady, N., Adams, R. B. Jr, Ozono, H., Nakashima, S., Yoshikawa, S., et al. (in press). Polling the face: Prediction and consensus across cultures. Journal of Personality and Social Psychology, 98, 1-15.

Rule, N. O., Ambady, N., \& Hallett, K. C. (2009). Female sexual orientation is perceived accurately, rapidly, and automatically from the face and its features. Journal of Experimental Social Psychology, 45, 1245-1251.

Scherer, K. R., Johnstone, T., \& Klasmeyer, G. (2003). Vocal expression of emotion. In R. J. Davidson, K. R. Scherer \& H. G. Goldsmith (Eds.), Handbook of Affective Sciences (pp. 443-456). Oxford, UK: Oxford University Press.

Todorov, A., Mandisodza, A. N., Goren, A., \& Hall, C. C. (2005). Inferences of competence from faces predict election outcomes. Science, 308, 1623-1626.

Zebrowitz, L. A. (1997). Reading Faces: Window to the Soul? Boulder, CO: Westview.

Zebrowitz, L. A., Andreoletti, C., Collins, M. A., Lee, S. Y., \& Blumenthal, J. (1998). Bright, bad, babyfaced boys: Appearance stereotypes do not always yield self-fulfilling prophecy effects. Journal of Personality and Social Psychology, 75, 1300-1320.

Zebrowitz, L. A., Brownlow, S., \& Olson, K. (1992). Baby talk to the babyfaced. Journal of Nonverbal Behavior, 16, 143-158.

Zebrowitz, L. A., \& McDonald, S. M. (1991). The impact of litigants' baby-facedness and attractiveness on adjudications in small claims courts. Law and Human Behavior, 15, 603-623.

Zebrowitz, L. A., \& Montepare, J. M. (1992). Impressions of babyfaced individuals across the life span. Developmental Psychology, 28, 1143-1152.

Zebrowitz, L. A., \& Montepare, J. M. (2006). The ecological approach to person perception: Evolutionary roots and contemporary offshoots. In M. Schaller, J. A. Simpson \& D. T. Kenrick (Eds.), Evolution and Social Psychology (pp. 81-113). New York: Psychology Press.

Zebrowitz, L. A., Montepare, J. M., \& Lee, H. K. (1993a). They don't all look alike: Individuated impressions of other racial groups. Journal of Personality and Social Psychology, 65, 85-101.

Zebrowitz, L. A., Olson, K., \& Hoffman, K. (1993b). Stability of babyfaceness and attractiveness across the life span. Journal of Personality and Social Psychology, 64, 453-466. 